\title{
REVIEW
}

\section{Oxime reactivation of acetylcholinesterase inhibited by toxic phosphorus esters: in vitro kinetics and thermodynamics}

\author{
Jiří Patočka ${ }^{1,2}$, Jiří Cabal $^{1}$, Kamil Kuča ${ }^{1}$, Daniel Jun ${ }^{1}$ \\ ${ }^{1}$ Department of Toxicology, Faculty of Military Health Sciences, University of Defence, Hradec Králové, Czech \\ Republic \\ ${ }^{2}$ Department of Radiology and Toxicology, Faculty of Health and Social Studies, University of South Bohemia, \\ České Budějovice, Czech Republic
}

Received $3^{\text {rd }}$ February 2005.

Revised $8^{\text {th }}$ March 2005.

Published online $15^{\text {th }}$ May 2005

\begin{abstract}
Summary
Owing to the threat of organophosphate exposures, not only to pesticides but also to nerve agents, it is very important to know the whole process of organophosphates-inhibited acetylcholinesterase (AChE, EC 3.1.1.7) reactivation. Although current antidotes against organophosphorus intoxications consist also of prophylactics, AChE reactivators are still needed especially in the case of intoxications with high doses of organophosphates, for which prophylactic treatment is not effective. For this reason, new AChE reactivators are still being developed. Our work summarizes accurately the whole reactivation process, and offers some help for scientists who are interested in the area of AChE reactivation.
\end{abstract}

Keywords: acetylcholinesterase - reactivation - nerve agents - in vitro - kinetics - thermodynamics oximes

\section{INTRODUCTION}

Acetylcholinesterase (AChE, EC 3.1.1.7) is a crucial enzyme in the human body (Patočka et al. 2004). It is affiliated with Alzheimer's and Parkinson's diseases and with many other degenerative disorders. AChE is the key enzyme that is targeted by organophosphate chemical warfare agents. AChE catalyzes the hydrolysis

Kamil Kuča, Department of Toxicology, School of Military Health Sciences, Třebešská 1575, University of Defence, 50001 Hradec Králové, Czech Republic

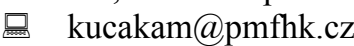

of the neurotransmitter acetylcholine and terminates the impulse transmission at cholinergic synapses. Organophosphates known as the nerve agents - the chemical compounds with most military significance - are irreversible inhibitors of AChE. They are extremely toxic. The inhibition of AChE by organophosporus compounds could result in severe intoxication and death of the exposed individual. These compounds block the active site of the enzyme by covalent bond to the serine hydroxygroup oxygen. The complex of AChE and organophosphate can be reversed by introducing an AChE reactivator (called "oxime") into the system. Dissociated oximes were shown to be able to restore organophosphate-inhibited AChE and greatly attenuate the toxicity of many highly toxic 
organophosphates. Therefore, these compounds are known as reactivators of phosphorylated AChE. Reactivation of organophosphate-inhibited AChE by oximes is the primary reason for their effectiveness in the treatment of organophosphate, especially nerve agents poisoning. That is why oxime reactivators are very important therapeutics (Bajgar 2004a). The objective of this review is a description of the kinetics and thermodynamics of the reactivation process and the different factors on which it depends.

\section{ACETYLCHOLINESTERASE}

$\mathrm{AChE}$ is a serine hydrolase that belongs to the esterases family within the higher eukaryotes. This family acts on different types of carboxylic esters. The biological role of $\mathrm{AChE}$ is the termination of impulse transmissions at cholinergic synapses within the nervous system by rapid hydrolysis of the neurotransmitter acetylcholine (Schumacher et al. 1986). The monomer of AChE with a molecular weight around 60000 is an ellipsoidal molecule, the size of which is approximately $45 \times 60 \times 65$ angstroms, consisting of a 12 stranded central mixed beta sheet surrounded by 14 alpha helices (Sussman et al. 1991). Each monomer contains one catalytic center composed of two compartments: the esteratic subsite containing the catalytic triad and the anionic subsite that accommodates the positive quaternary compartment of acetylcholine. The esteratic subsite contains the catalytic machinery of the enzyme: a catalytic triad of Ser 200, His 440, and Glu 327. The anionic subsite is defined by Trp 84, Phe 330, and Phe 331. Its role is to orient the charged part of the substrate that enters the active center. This role is the main function of the Trp residue (Sussman et al. 1991). The recent rendition of the x-ray structure for AChE places the active catalytic site deep within a gorge-like fold of the protein. The aromatic gorge in the protein is approximately 20 angstroms deep and penetrates halfway into the enzyme. The active site lies at the base of this gorge only 4 angstroms above the base, leading some to label this the 'active gorge'. The 'aromatic' gorge is a more appropriate term, though, because $40 \%$ of its lining is composed of 14 aromatic residua located in the gorge which is highly conserved from different species of AChE (Harel et al. 1993). The high aromatic content of the walls and floor may explain why studies have proposed hydrophobic and anionic binding sites independent of the active site. Only a few acidic residues are present within the gorge. The aromatic residues clearly play an important role in the stabilization of the complex. Electrostatic as well as hydrophobic effects are of importance here (Berman and Leonard 1990). The electrostatic potential map of AChE suggests that this enzyme, possibly like other enzymes with charged substrates, steers its substrate toward its gorge and into the active site.

The second anionic site of AChE, the so-called 'peripheral' anionic site is located at the active center gorge entry, encompasses overlapping binding sites for different activators and inhibitors. The peripheral anionic site consists of the residues Asp 74 and Trp 286 as a common core. Binding of ligands to these residues may be the key to the allosteric modulation of $\mathrm{AChE}$ catalytic activity (Bourne et al. 2003).

\section{TOXIC PHOSPHORUS ESTERS AND ACHE}

The organophosporus compounds have drawn the interest of biochemists, physiologists, agriculturists and especially military chemists: all highly toxic organophosphorus chemical warfare agents (called nerve agents) are strong inhibitors of AChE. As mentioned above, these compounds irreversibly bind to AChE in the place of its catalytic center, causing the phosphorylation of the enzyme and subsequent inhibition of its activity. The normal function of $\mathrm{AChE}$ is to hydrolyse the neurotransmitter acetylcholine (ACh), which is released on the neural junction. Inhibition of the enzyme results in the accumulation of excessive concentrations of $\mathrm{ACh}$ at neural receptors. This accumulation at the endings of motor nerves to voluntary muscles and in some autonomic ganglia, results in nicotinic signs and symptoms, and its accumulation in the brain and spinal cord results in characteristic central nervous system symptoms (Bajgar 2004a, Bajgar 2004b).

\section{INTERACTION OF ORGANOPHOSPHATES WITH ACHE}

AChE reacts with organophosphorus compounds having the general structure I, II and III.

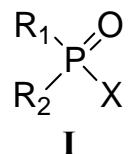<smiles>[R]OP([R20])([X])=O</smiles>

II<smiles>[R]OP([R])(=O)O</smiles> 
In many organophosphates of this type, $\mathrm{R}_{1}$ and $\mathrm{R}_{2}$ are an alkyl, dialkylaminoalkylthio or dialkylamido group, and $\mathrm{X}$ a halogen, cyanide, paranitrophenoxy, phenoxy, dialkylaminoalkylthio, or other similar group (Cabal 1992). There are three principle reactions involved in enzyme-phosphate interaction: phosphorylation of the enzyme (1), reversal of inhibition (2), and aging (3).

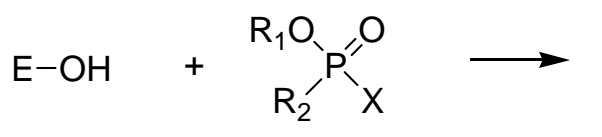

where E-OH represents a part of the esteratic site of AChE. The formation of acetylated enzyme by the binding of the acetyl group from Ach to a basic group of the esteratic site is considered as the ratedetermining step in this sequence of reaction. The acetylated enzyme is extremely unstable and has a half-life of a fraction of a millisecond. Phosphorylated AChE, unlike acetylated AChE, is<smiles>[R]OP([R2])(=O)OF</smiles>
$\underset{\substack{\text { Extremly } \\ \text { slow }}}{\longrightarrow}$

The chemical bond between the oxygen atom in enzyme and the phosphorus atom in organophosphate is very strong, the nucleophilicity of water molecule is too weak and dephosphorylation of enzyme, i.e., spontaneous reactivation of its activity is extremely slow. The reversal of the activity connected with dephosphorylation of AChE, can be accelerated by some strong nucleophilic agents. These compounds performed induced reactivation and are known as reactivators of the organophosphate-inhibited AChE. These agents are used as antidotes for the treatment of intoxications by toxic organophosphorus compounds.

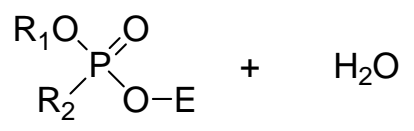

\section{Aging}

\section{PHOSPHORYLATION OF ACHE}

The most important feature of many organophosphates is their ability to react with $\mathrm{AChE}$ at very low concentrations. This irreversible action may be described as a bimolecular reaction as follows:

$$
\mathrm{E}+\mathrm{P} \stackrel{k_{\mathrm{i}}}{\longrightarrow} \mathrm{EP}
$$

It is possible to calculate the first-order rate constants $\left(k_{\mathrm{obs}}\right)$ by linear regression for any given
Phosphorylation of the enzyme is characterized by the formation of a chemical bond between the phosphorus atom of organophosphate and the oxygen atom of the hydroxyl group of serine in the catalytic center of AChE. The reaction between organophosphates and $\mathrm{AChE}$ is analogous to the reaction between $\mathrm{ACh}$ and $\mathrm{AChE}$, and can be represented as follows:<smiles>[R]OP([R2])(=O)OF</smiles>

extremely stable. Therefore, the inhibition of AChE by organophosphorus compounds, especially nerve agents, is called irreversible.

Reversal of inhibition, i.e. reaction (2), proceeds at a very low rate, and for this reason, organophosphates are inhibitors and not substrates of AChE.<smiles>[R]OP([R])(=O)O</smiles>

Spontaneous reactivation is the combination of two parallel processes: dephosphorylation and aging. Aging is the formation of a fully irreversible form of the phosphorylated $\mathrm{AChE}$ in consequence of dealkylation of the O,O-dialkyl-phosphorylated or O-alkyl-phoshonylated enzyme. An aged enzyme cannot be reactivated by the reactivators of organophosphate-inhibited AChE. Aging is defined as dealkylation of the phosphoryl adduct to give a negatively charged adduct that is stabilized by interaction with the catalytic His 440 (Millard et al. 1999). Aging irreversibly prevents dephosphorylation and limits the amount of the enzyme that becomes reactivated.

$$
\mathrm{R}_{2}^{\mathrm{HO}}=\mathrm{O}=\mathrm{O}
$$

inhibitor concentration using the formula: where $v_{0}$ and $v_{\mathrm{i}}$ are enzyme activities in the absence and in the presence of the inhibitor (I) at the time $t$ (Aldridge and Reiner 1969). The second-order inhibition rate constant $\left(k_{\mathrm{i}}\right)$ is calculated from the linear dependency of $k_{\text {obs }}$ from the inhibitor concentration:

$$
\begin{gathered}
\ln \left(v_{0} / v_{\mathrm{i}}\right)=k_{\mathrm{obs}} t \\
k_{\mathrm{i}}=k_{o b s} /[\mathrm{I}]
\end{gathered}
$$


The value of $k_{\mathrm{i}}$ reaches values from $10^{-7}$ to $10^{-8}$ L. $\mathrm{mol}^{-1} \mathrm{~min}^{-1}$ for strong organophosphate inhibitors. The energy of activation ( $E_{\text {act }}$ ) of the inhibitory reaction is in the correct range for a chemical reaction, e.g., $10.6 \mathrm{kcal}_{\mathrm{mol}}{ }^{-1}$ for paraoxon against erythrocytal AChE (O'Brien 1960).

The reaction of organophosphate with $\mathrm{AChE}$ is progressive, i.e., the longer the inhibitor is in contact with the enzyme, the greater is the inhibition. The molar concentration of the inhibitor that gives $50 \%$ enzyme inhibition is called the $I_{50}$. This parameter, and also the so-called $\mathrm{pI}_{50}$ (the negative common logarithm of the $\mathrm{I}_{50}$ ), is timedependent, and therefore, is not definitive unless the incubation time is known. The correct parameter to use is the bimolecular rate constant $\mathrm{k}_{\mathrm{i}}$ at a fixed temperature and $\mathrm{pH}$. In fact these two terms are interconvertible, where $t$ is the incubation time. The $I_{50}$ is far more popular in the literature because its units (i.e. molar concentration) are readily pictured and mentally manipulated, whereas

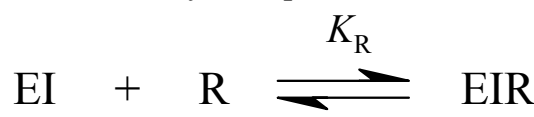

where EI is the phosphorylated and/or phosphonylated enzyme, $\mathrm{R}$ the reactivator, EIR the intermediary complex, $\mathrm{P}$ the reaction product, and E the enzyme. $K_{\mathrm{R}}$ is the dissociation constant of complex EIR and $k_{\mathrm{R}}$ the decomposition rate of this complex. The rate of reactivation at any moment depends on the oxime concentration and the amount of still not reactivated enzyme.

$$
\begin{gathered}
\frac{1}{k_{a p p}}=\frac{1}{k_{R}}+\frac{K_{R}}{k_{R}[R]} \\
k_{r}=\frac{k_{R}}{K_{R}}
\end{gathered}
$$

A relation is usually derived for the calculation of these constants, which is identical with the equation characterizing the relation between the rate of the enzymatic reaction and the concentration of the substrate under the conditions of Michaelis kinetics. This equation in the following form permits the calculation of $K_{\mathrm{R}}$ and $k_{\mathrm{R}}$ and also of the bimolecular rate constant of reactivation for $[\mathrm{R}]<<$ $K_{\mathrm{R}}$, when we plot the reciprocal values of $k_{\text {app }}$ versus the reciprocal values of [R].

$$
k_{i}=\frac{2.303}{t} \log \frac{v_{o}-v_{r}}{v_{o}-v_{i}}
$$

The apparent rate constant $k_{\text {app }}$ can be calculated from the equation where $v_{0}$ and $v_{\mathrm{i}}$ are the enzyme activities in the absence and in the presence the units of $\mathrm{k}_{\mathrm{i}}$ (i.e., L.minutes ${ }^{-1}$ moles $^{-1}$ ) are hardly interpreted.

$$
k_{i}=\frac{\ln 2}{I_{50} . t}=\frac{0.695}{I_{50} . t}
$$

\section{KINETICS OF REACTIVATION OF ORGANOPHOSPHATE-INHIBITED ACHE}

AChE that is inhibited by organophosphates can be reactivated by some nucleophilic compounds if it hasn't undergone a prior aging reaction. There is evidence that in the course of reactivation an intermediary complex between reactivator and inhibited enzyme is first formed. The kinetics of the reactivation process follows second-order kinetics and can be described schematically by the followed equation:

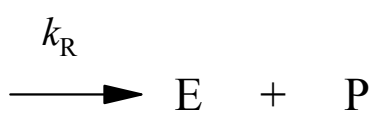

of the inhibitor and $v_{\mathrm{r}}$ is the enzyme activity in the presence of the reactivator.

Likewise as the inhibition effect can be expressed by $\mathrm{I}_{50}$ value, the reactivation effect can also be qualified as a reactivator concentration able to restore $50 \%$ of inhibited enzyme in time $t\left(\mathrm{R}_{50}\right)$. This value (or other similar values, for example $R_{10}$, $\mathrm{R}_{90}$ ) are easily available from the percentage dependence of reactivated enzyme on reactivator concentration (Patočka 1972a). The percentage of the reactivated enzyme can be estimated from the following equation:

$$
\%_{\text {reactivation }}=100-100\left(v_{0}-v_{\mathrm{R}}\right) /\left(v_{0}-v_{\mathrm{i}}\right)
$$

\section{Oxime reactivators}

Reactivators based on the oxime structure were discovered in the middle of the last century, when stronger nucleophilic reagents than water were synthesized. The most potent effect was produced when the reactivating oxime group was attached to a residue containing a quaternary nitrogen group, at a distance from the reactivating group similar to the distance between the anionic and esteratic site of AChE. Presumably, this conformation helps with the affinity of the reactivator molecule towards the active center of AChE.

The first practically available oxime reactivator was prepared independently and almost simultaneously by Wilson and Ginsburg (1955) in the USA, and by Childs et al. (1955) in Great Britain. It was 2-hydroxyiminomethyl-1methylpyridinium iodide known as 2-PAM or pralidoxime (IV) (Fig. 1). 
<smiles>C[n+]1ccccc1C=[I+]</smiles>

IV<smiles>ON=Cc1cc[n+](CCC[n+]2ccc(C=NO)cc2)cc1</smiles>

$2 \mathrm{Br}-$<smiles>C[n+]1ccc(C(N)=O)cc1</smiles>

VII

$$
\begin{gathered}
\text { V } \quad \mathrm{A}=\mathrm{CH}_{2} \\
\text { VI } \mathrm{A}=\mathrm{O}
\end{gathered}
$$

Fig. 1. Structures of currently used AChE reactivators

Further Hobbiger et al. (1958) reported some new compounds, which were up to 22 times more potent than 2-PAM in reactivating organophosphate-inhibited AChE. These resembled two units of 2-PAM or 4-PAM (4hydroxyiminomethyl-1-methylpyridinium iodide), joined at their quaternary nitrogen groups by a carbon chain, optimally 3 carbons long. These are for example 1,3-bis-(4- hydroxyiminomethylpyridinium)propane dibromide (TMB-4; trimedoxime, V) or 1,3-bis-(4hydroxyiminomethylpyridinium) 2-oxapropane dichloride (LüH6; obidoxime; Toxogonin $®$, VI) (Fig. 1). These compounds are known as bisquaternary pyridinium aldoximes. The mechanism of the reactivation process is shown in Fig 2.

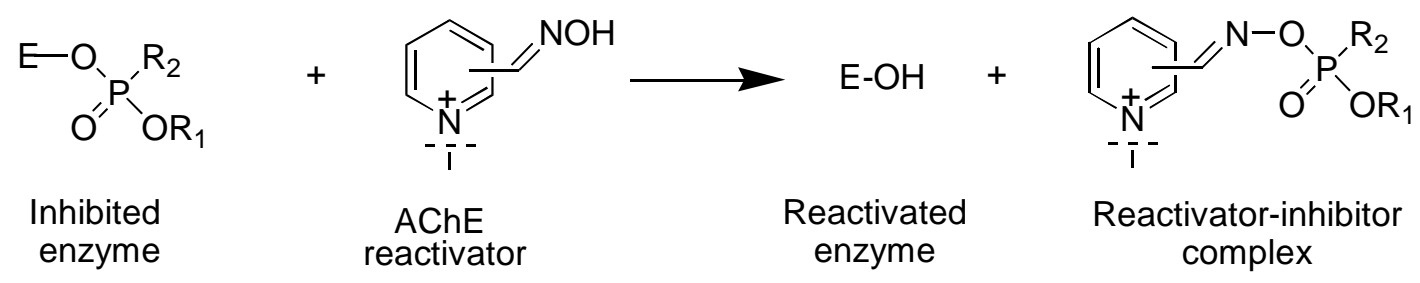

Fig. 2. Oxime reactivation of the organophosphate-inhibited AchE

Further, it was found that presence of a second aldoxime moiety in the reactivator molecule is not necessary for its reactivation potency. However, the presence of the second quaternary nitrogen increases the affinity of the reactivator toward the intact and inhibited AChE. Such a potent reactivator is bisquaternary monoaldoxime such as (1-(2-hydroxyiminomethylpyridinium)-3-(4carbamoylpyridinium)-2-oxapropane dichloride) (HI-6, VII) (Figure 1). Also newly synthesized reactivators $\quad-\quad \mathrm{K} 027 \quad$ (1-(4hydroxyiminomethylpyridinium)-3-(4carbamoylpyridinium) propane dibromide) and K048 (1-(4-hydroxyiminomethylpyridinium)-4-(4carbamoylpyridinium) butane dibromide) are usually compounds of this type (Kuča et al. 2003a, Kuča et al 2003b).

Oxime reactivators of organophosphateinhibited AChE are believed to give rise to phosphorylated oximes that reinhibit the enzyme. It was demonstrated that phosphorylated oximes that were generated in situ were more potent inhibitors of AChE than the parent organophosphate (Leader et al. 1999).

\section{THE INFLUENCE OF OXIME REACTIVATORS ON INTACT ACHE}

The affinity of oxime reactivators to the active center of AChE entails the action of these compounds as reversible competitive inhibitors of AChE. From the results with a homologous series of reactivators of the general structure $\alpha, \omega$-bis-(4hydroxyiminomethylpyridinium)-polymethylene dihalogenide, it was found that during the binding of these compounds to the active center of $\mathrm{AChE}$, both electrostatic forces and hydrophobic is implicit in the curve of dependence of percentage reactivation on reactivator concentration (Fig. 3). 


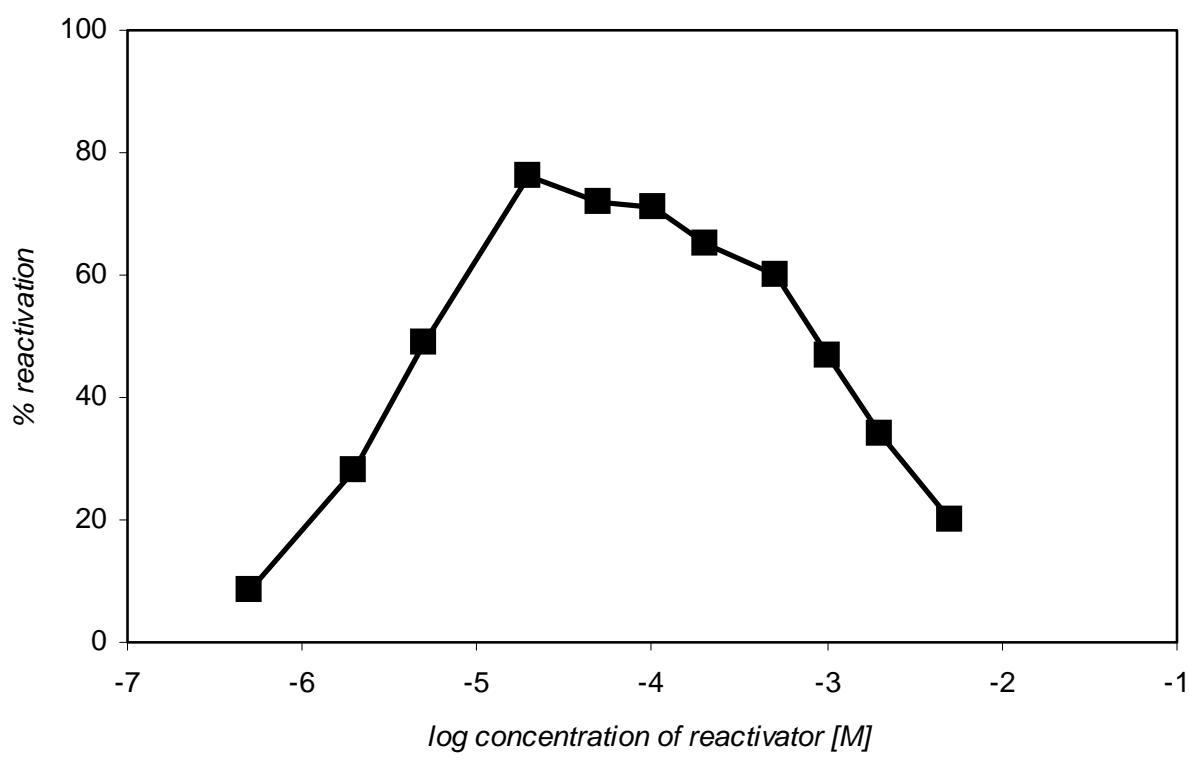

Fig. 3. Reactivation curve of HI-6 (Source of the enzyme - rat brain homogenate; AChE inhibitior - sarin; time of inhibition $-30 \mathrm{~min}$; time of reactivation $-10 \mathrm{~min}$; $\mathrm{pH} 8$; temperature $-+25^{\circ} \mathrm{C}$ )

This curve is bell-shaped (Kuča and Kassa 2003). The first - increasing - part of the curve characterizes reactivation of the inhibited enzyme. On the other hand, the second - decreasing - part describes inhibition of the enzyme by the excess of the reactivator.

\section{THE INFLUENCE OF PH ON KINETICS OF OXIME REACTIVATION}

The regeneration of organophosphate-inhibited AChE by oximes is strongly dependent on $\mathrm{pH}$. It is obvious, because only dissociated anion of oxime is able to break the bond between the organothosphorus inhibitor and the enzyme. It was deduced from the kinetic constants of reactivation obtained at different $\mathrm{pH}$ values that the decrease of $k_{\mathrm{R}}$ values is dependent on $\mathrm{pH}$. The intermediate complex EIR is more stable at higher $\mathrm{pH}$ therefore $k_{\mathrm{R}}$ values increase when $\mathrm{pH}$ decreases (Patočka and Bielavský 1972b).

The values of $K_{\mathrm{R}}$ are dependent on $\mathrm{pH}$, as the reactivation process is essentially ionic in nature, involving a protonated form of the inhibited enzyme and polar ion of the reactivator. The $\mathrm{pH}$ optimum of the reactivation process can be expressed as midway between $p K_{\mathrm{a}}$ of the oxime group of reactivator and $p K_{\mathrm{EI}}$ of the organophosphate-inhibited enzyme.

$$
p H_{o p t}=\frac{p K_{a}+p K_{E I}}{2}
$$

The location of $p H_{\text {opt }}$ is in the physiological range of $\mathrm{pH}$ (Davies and Green 1956, Patočka and Bielavský 1972b).

\section{THE INFLUENCE OF TEMPERATURE ON S}

The kinetic constant values of reactivation are commonly dependent on temperature, as are other enzyme-catalyzed reactions with higher temperature limitation of protein denaturation. It is possible to describe the dependence of the kinetic constant on reaction temperature by some thermodynamic functions but credible values for the reactivation process are very rare in the literature. The values of the standard free energy of binding $\left(\Delta \mathrm{G}^{0}\right)$ were calculated in experiments with the reactivation of sarin-inhibited AChE by $\alpha, \omega$-bis-(4-hydroxyiminomethylpyridinium)-2trans-butene dibromide (Patočka 1972b) from the equation

$$
\Delta G=-R T \ln K_{R}
$$

in a temperature interval from 5.2 to $40.8^{\circ} \mathrm{C}$, where $\mathrm{R}$ is the universal gas constant and $\mathrm{T}$ is the absolute temperature. The standard enthalpy of binding $\left(\Delta \mathrm{H}^{0}\right)$ were calculated according to the equation

$\log K_{R}=-\frac{\Delta H^{\circ}}{2.303 R} \cdot \frac{1}{T}+$ constant 
from the linear plot of $\log K_{\mathrm{R}}$ against $1 / \mathrm{T}$, where a slope of this line is $\Delta \mathrm{H}^{0} / 2.303 \mathrm{R}$. It was demonstrated that the dependence of $\log K_{\mathrm{R}}$ on temperature is significant up to a transition temperature of $27^{\circ} \mathrm{C}\left(\Delta \mathrm{H}^{0}=8.44 \mathrm{kcal} / \mathrm{mol}\right)$. Beyond this point there is no significant temperature dependence of enthalpy change $\left(\Delta \mathrm{H}^{0}=\right.$ $0)$. The values for the standard entropy changes $\left(\Delta \mathrm{S}^{0}\right)$ were calculated by substituting $\Delta \mathrm{H}^{0}$ and $\Delta \mathrm{G}^{0}$ in the equation and their values proceed from +4.95 e.u. at temperature $5.2^{\circ} \mathrm{C}$ to +2.20 e.u. at temperature $40.8^{\circ} \mathrm{C}$.

\section{STRUCTURE - ACTIVITY RELATIONSHIPS}

The discovery of the relationship between structure and the reactivation potency of $\mathrm{AChE}$ reactivators is not well documented. Some authors use computer-aided calculations for the prediction of new more potent AChE reactivators (Mager 1981, Mager 1983, Mager and Weber 2004, Dohnal et al. 2003). There are four important structural factors, which influence the affinity of the AChE reactivators toward inhibited $\mathrm{AChE}$.

The presence of quaternary nitrogen in the molecule of reactivator is the first well-known factor. Moreover, a molecule with two quaternary nitrogens achieved higher affinity toward inhibited AChE compared to monoquaternary compounds (Kuča and Kassa 2003).

The length of the connecting chain between both pyridinium rings by the bisquaternary pyridinium reactivator plays an important role in its potency (Patočka and Bielavský 1972a, Pang et al. 2003, Kuča et al. 2003c). Owing to this fact, it can be designed as the second structural factor. There is a dependence between the length of the linking chain and nerve agent used (Kuča et al. 2003c). For example, the ideal length of connecting chain for reactivation of tabun, sarin or VX inhibited AChE is 3 or 4 methylene groups. On the other hand, methoxime (containing one methylene group) seems to be the most potent reactivator of cyclosarin inhibited AChE (Kassa and Cabal 1999; Kuča et al. 2003c).

The presence of the oxime group in the structure of the reactivator is other substantial structural factor. Formerly, hydroxyiminoacetone, hydroxamic acids, geminal dioles, and ketoximes were used as potential nucleophilic agents for breaking the bond between inhibitor and enzyme (Heath 1961; Cabal et al 1998, Kuca et al. 2004a). The aldoxime group seems to be currently the most used, and therefore it is involved in all newly synthesized AChE reactivators.

The last important structural factor is also connected with the oxime group. It is the position of the oxime group at the quaternary pyridinium ring. It is generally known that position two and four are more suitable compared to position three. This fact is due to the difference in $p K_{\mathrm{a}}$ between oximes in position two and four as against those in position three (Heath 1961). The position of the oxime group is nerve agent dependent as well as the length of the connecting chain between the quaternary pyridinium rings. For example, cyclosarin inhibited $\mathrm{AChE}$ is best reactivated by reactivators with oxime in position two (Kuča and Patočka 2004). On the other hand, reactivators with the oxime group at the pyridinium ring in position four are currently considered to be the most potent for reactivation of tabun-inhibited $\mathrm{AChE}$ (Cabal et al. 2004).

\section{CONCLUSION}

Owing to the threat of organophosphate exposures, not only to pesticides but also nerve agents, it is very important to know the whole process of organophosphates-inhibited AChE reactivation. Although current antidotes against organophosphorus intoxications consist also of prophylactics, AChE reactivators are still needed, especially in the case of intoxications with high doses of organophosphates, for which prophylactic treatment is not effective. For this reason, new AChE reactivators are still being developed.

Our work summarizes accurately the reactivation process, and should be some help for scientists who are interested in the area of AChE reactivation.

\section{ACKNOWLEDGEMENT}

This work was supported by grant of Ministry of Defense (Czech Republic) No. ONVLAJEP20031.

\section{REFERENCES}

Aldridge W.N., Reiner E.: Acetylcholinesterase. Two types of inhibition by an organophosphorus compound: one the formation of phosphorylated enzyme and the other analogous to inhibition by substrate. Biochem. J. 115:147-162, 1969.

Bajgar J.: Organophosphates/nerve agents poisoning: mechanism of action, diagnosis, prophylaxis and treatment. Adv. Clin. Chem. 38:151-216, 2004.

Bajgar J.: Prophylaxis against organophosphorus poisoning. J. Med. Chem. Def. 1:1-16, 2004. 
Berman H.A., Leonard K.: Ligand exclusion on acetylcholinesterase. Biochemistry 29:1064010649, 1990.

Bourne Y., Taylor P., Radic Z., Marchot P.: Structural insight into ligand interactions at the acetylcholinesterase peripheral anionic site. EMBO J 22:1-12, 2003.

Cabal J.: Comparison of dialkylamidofluorphosphate acid esters features with other fluoroorganophosphates. Voj. Zdrav. Listy 61:215-221, 1992. (In Czech)

Cabal J., Hampl F., Liska F. et al.: Hydrates of quaternary ammonium aldehydes as potential reactivators of sarin-inhibited acetylcholinesterase. 63:1021-1030, 1998.

Cabal J., Kuča K., Kassa J.: Specification of the structure of oximes able to reactivate tabun inhibited acetylcholinesterase. Pharmacol. Toxicol. 95:81-86, 2004.

Childs A.F., Davies D.R., Green A.L., Rutland J.P.: The reactivation by oximes and hydroxamic acids of cholinesterase inhibited by organo-phosphorus compounds. Br. J. Pharmacol. 10:462-465, 1955.

Davies D.R., Green A.L.: The kinetics of reactivation, by oximes, of cholinesterase inhibited by organophosphorus compounds. Biochem. J. 63:529-535, 1956.

Dohnal V., Kuča K., Havel J., Cabal J.: Prediction of new efficient cyclosarin-inhibited acetylcholinesterase reactivators structures using method of arteficial neural networks. Chem. Listy 97:1201-1202, 2003.

Harel M., Schalk I., Ehret-Sabatier L. et al.: Quaternary ligand binding to aromatic residues in the active-site gorge of acetylcholinesterase. Proc. Natl. Acad. Sci. USA 90: 9031-9035, 1993.

Heath D.F.: Organophosphorus Poisons: Anticholinesterases and Related Compounds. Pergamon Press, Oxford 1961, pp.403.

Hobbiger F., O'Sullivan D.G., Sadler P.W.: New potent reactivators of acetylcholinesterase inhibited by tetraethyl pyrophosphate. Nature 182:1498-1499, 1958.

Kassa J., Cabal J.: A comparison of the efficacy of acetylcholine reactivators against cyclohexyl methylphosphonofluoridate (GF agent) by in vitro and in vivo methods. Pharmacol. Toxicol. 84:41-45, 1999.

Kuča K., Bielavský J., Cabal J., Bielavská M.: Synthesis of a potential reactivator of acetylcholinesterase $1-(4-$ hydroxyiminomethylpyridinium)-3(carbamoylpyridinium)-propane dibromide. Tetrahedron Lett. 44:3123-3125, 2003a.

Kuča K., Bielavský J., Cabal J., Kassa J.: Synthesis of a new reactivator of tabun inhibited acetylcholinesterase. Bioorg. Med. Chem. Lett. 13:3545-3547, 2003b.
Kuča K., Patocka J., Cabal J.: Reactivation of organophosphate inhibited acetylcholinesterase activity by $\quad \alpha, \omega$-bis-(4hydroxyiminomethylpyridinium)alkanes in vitro. J. Appl. Biomed. 1:207-211, 2003c.

Kuča K., Pícha J., Cabal J., Liška F.: Synthesis of the three monopyridinium oximes and evaluation of their potency to reactivate acetylcholinesterase inhibited by nerve agents. J. Appl. Biomed. 2:51-56, 2004.

Kuča K., Kassa J.: A Comparison of the ability of a new bispyridinium oxime - 1-(4hydroxyiminomethylpyridinium)-4-(4-

carbamoylpyridinium)butane dibromide and currently used oximes to reactivate nerve agentinhibited rat brain acetylcholinesterase by in vitro methods. J. Enzyme Inhib. Med. Chem. 18:529535, 2003.

Kuča K., Patočka J.: Reactivation of cyclosarininhibited rat brain acetylcholinesterase by pyridinium-oximes. J. Enzyme Inhib. Med. Chem. 19:39-43, 2004.

Leader H., Vincze A., Manisterski B. et al.: Characterization of O,O-diethylphosphoryl oximes as inhibitors of cholinesterases and substrates of phosphotriesterases. Biochem. Pharmacol. 58:503-15, 1999.

Mager P.P.: Quantitative structure-reactivity and structure-toxicity relationships of reactivators ofager P.P.: QSAR applied to aging of phosphylated acetylcholinesterase. Pharmazie 36:450-451, 1981.

Mager P.P.: QSAR applied to aging of phosphylated acetylcholinesterase. Pharmazie 38: 271-272, 1983.

Mager P.P., Weber A.: Structural Bioinformatics and QSAR Analysis Applied to the Acetylcholinesterase and Bispyridinium Aldoximes. Drug Des. Dis. 18:127-150, 1983.

Millard C.B., Kryger G., Ordentlich A. et al.: Crystal structures of aged phosphonylated acetylcholinesterase: nerve agent reaction products at the atomic level. Biochemistry 38:7032-7039, 1999.

O'Brien R.D.: Toxic Phosphorus Esters. Academic Press, New York, London 1960, pp. 74.

Pang Y.P., Kollmeyer T.M., Hong F. et al.: Rational design of alkylene-linked bispyridiniumaldoximes as improved acetylcholinesterase reactivators. Chem. Biol. 10:491-502, 2003.

Patočka J.: Reactivation of isopropylmethylphosphonylated rat brain acetylcholinesterase by oximes. Coll. Czech. Chem. Commun. 37:899-906, 1972a.

Patočka J.: Reactivation of isopropylmethylphosphonylated acetylcholinesterase by $\alpha, \omega$-bis-(4-hydroxyiminomethylpyridinium)-2trans-butene dibromide. The effect of 
temperature. Biochem. Pharmacol. 21:31923196, 1972b.

Patočka J., Bielavský J.: Afinity of bis-quaternary pyridiniumaldoximes for the active centre of intact and isopropylmethylphosphonylated acetylcholinesterase. Coll. Czech. Chem. Commun. 37:2110-2116, 1972a.

Patočka J., Bielavský J.: Reactivation of isopropylmethylphosphonylated acetylcholinesterase by $\alpha, \omega$-bis-(4-hydroxyiminomethylpyridinium)-2trans-butene dibromide - The effect of $\mathrm{pH}$. Biochem. Pharmacol. 21:742-745, 1972b.

Patočka J., Kuča K., Jun D.: Acetylcholinesterase: crucial enzyme of human body. Acta Medica (Hradec Kralove) 47:215-230, 2004.
Schumacher M., Camp S., Maulet Y. et al.: Primary structure of Torpedo californica acetylcholinesterase deduced from its cDNA sequence. Nature 319:407-409, 1986.

Sussman J.L., Harel M., Frolow F. et al.: Atomic structure of acetylcholinesterase from Torpedo californica: a prototypic acetylcholine-binding protein. Science 253:872-879, 1991.

Wilson I.B., Ginsburg S.: A powerful reactivator of alkylphosphate-inhibited acetylcholinesterase. Biochim. Biophys. Acta 18:168-170, 1955. 